\title{
The Association of Oral Health Status, demographic characteristics and socioeconomic determinants with Oral health-related quality of life among children: a systematic review and Meta- analysis
}

Ladan Fattah Moghaddam ${ }^{1}$, Mario Vianna Vettore ${ }^{2}$, Azadeh Bayani ${ }^{3}$, Amir-Hossien Bayat ${ }^{4}$, Elahe Ahounbar ${ }^{5}$, Morteza Hemmat ${ }^{4}$, Bahram Armoon ${ }^{4^{*}}$ (i) and Yadolah Fakhri ${ }^{6}$

\begin{abstract}
Background: Health-related quality of life (HQoL) indicators are considered valid measures of patient assessment in physical, mental and oral healthcare. This study aimed to examine the evidence on the relationship of oral health status, demographic and socioeconomic characteristics with oral health-related quality of life (OHRQoL) in children.

Methods: Studies in English published up to December 2019 were searched on PsycINFO, PubMed, SciELO, Scopus, and Web of Science databases. Epidemiological studies simultaneously assessing sociodemographic factors related to oral health (age, income, gender, maternal education), oral health measures (orthodontic treatment needs, dental caries and periodontal disease) and OHRQoL in children aged 3-12 years were included. Methodological quality was assessed using a Critical Appraisal Checklist. Meta-analysis was used to estimate pooled measures between sociodemographic factors and oral health measures with OHRQOL.
\end{abstract}

Results: Eleven articles were included. Lower children's age ( $3-5$ years vs $>5)$, gender (girls vs boys), lower income $(<70 \$$ vs $\geq \$ 70$ ), low maternal education ( $\leq 6$ vs $>6$ years) were associated with poor OHRQoL among children. Orthodontic treatment needs, dental caries and periodontal diseases were also associated with poor children's OHRQoL. Meta-regression showed that Human Development Index, sample size, year of publication and participant's age were relevant aspects that influenced the above mentioned relationships.

Conclusions: Our findings suggest that oral health promotion strategies to improve children's OHRQoL should consider the social and environmental where they live as well their oral health status. Further longitudinal studies are needed to explore the determinants of OHQoL in children.

Keywords: Oral health, Quality of life, Children

\footnotetext{
* Correspondence: Bahramarmun@gmail.com

${ }^{4}$ Social Determinants of Health Research Center, Saveh University of Medical Sciences, Saveh, Iran

Full list of author information is available at the end of the article
}

\section{$\triangle B M C$}

(c) The Author(s). 2020 Open Access This article is licensed under a Creative Commons Attribution 4.0 International License, which permits use, sharing, adaptation, distribution and reproduction in any medium or format, as long as you give appropriate credit to the original author(s) and the source, provide a link to the Creative Commons licence, and indicate if changes were made. The images or other third party material in this article are included in the article's Creative Commons licence, unless indicated otherwise in a credit line to the material. If material is not included in the article's Creative Commons licence and your intended use is not permitted by statutory regulation or exceeds the permitted use, you will need to obtain permission directly from the copyright holder. To view a copy of this licence, visit http://creativecommons.org/licenses/by/4.0/ The Creative Commons Public Domain Dedication waiver (http://creativecommons.org/publicdomain/zero/1.0/) applies to the data made available in this article, unless otherwise stated in a credit line to the data. 


\section{Background}

The use of oral health-related quality of life (OHRQoL) in healthcare along with clinical assessment reflects a shift from normative approach to a patientcentred care perspective in the evaluation of oral health and the efficacy of dental treatment $[1,2]$. OHRoL indicators assess different dimensions of oral health status of the impact of oral conditions on physical, emotional, social and psychological aspects on a person's subjective well-being $[1,3]$. Previous research showed that OHRQoL may be influenced by oral health conditions, demographic and socioeconomic characteristics, and contextual factors such as political and cultural aspects [4]. Furthermore, children's oral health status can affect their well-being and quality of life as well as that of their parents.

Dental caries and periodontal disease are relevant public health problems that account for a considerable proportion of the global burden of oral diseases [5]. The etiology of oral diseases are multifactorial and their distribution and severity of oral diseases in children may vary according to family's socioeconomic condition [6]. Fisher-Owens and colleagues developed a theoretical framework involving relevant predictors of children's oral health that were grouped into community- familyand child-level influences [7]. They have shown the importance of socio-behavioral and environmental factors on children's oral health. Of them, family environment plays a central role in children's oral health [8].

Environmental and sociodemographic factors can influence OHRQoL in children and other age groups $[8$, 9]. Age [10], sex [11], socioeconomic status [12-14], socio-cultural factors $[10,15,16]$, psychosocial factors [17-19] were associated with OHRQoL. For instance, income and family structure were significant predictors of children's OHRQoL, independently of oral diseases [20]. Several studies suggest that oral diseases can impact on children and adolescents OHRQoL [21-24]. Locker (2007) showed that children from low-income families and those with only one adult in the household were more likely to poor OHRQoL [25]. Children from lowincome families also have poor general and oral health than those from better off families [26]. This study aimed to analyze the evidence on the association of oral health conditions (orthodontic treatment needs, dental caries and periodontal disease), demographic and socioeconomic characteristics (age, gender, income, maternal education) with oral health-quality of life in children.

\section{Methods}

The present systematic review was performed in accordance with Preferred Reporting Items for Systematic Reviews and Meta-Analyses (PRISMA) [27, 28].

\section{Eligibility criteria and PECO terms}

Epidemiologic studies concomitantly assessing sociodemographic factors related to oral health, oral health measures and children's OHRQoL in children were included. The PECO tool using the following terms were used: (a) Participants: children aged 3-12 years; (b) Exposures: orthodontic treatment needs, dental caries and periodontal disease, children's age, gender, family income, maternal education; (c) Comparison: non-children groups; (d) Outcomes: oral healthrelated quality of life. Only studies reporting quantitative measures and/or dental indices to assess oral health status (e.g. number of decayed, missing, and filled teeth [DMFT] for dental caries) [29], studies assessing OHRQoL through validated questionnaire, those reporting measures of association and published in English were included. In addition, only studies reporting data on severe oral health conditions, such as malocclusion, dental caries and periodontal disease, were considered. Investigations regarding temporomandibular disorders, erosion, or xerostomia were excluded. Studies comparing OHRQoL measures between genders, those considering the family income threshold of $70 \$$ and maternal education of 6 years of education were included. Only articles reporting coefficients and odds ratios were included. The methodological quality of the studies was also considered as inclusion criteria. Only studies considered of medium or high quality (at least three points on the Critical Appraisal Checklist for observational studies) were included [30].

\section{Search strategy and selection of studies}

The search strategy was based on $\mathrm{MeSH}$ terms according to PECO terms. Papers published up to December 2019 on PsycINFO, PubMed, SciELO, Scopus, Web of Science, and Cochrane electronic databases were screened for inclusion. Table 1 presents the search strategy, including the combination of key words used in the different electronic libraries. Exclusion of duplicate papers was conducted using EndNote X7 software (Thomson Reuters, New York, NY, USA).

Initially two researchers (A.B. and B.A.) screened the titles and abstracts of the retrieved papers independently according to the inclusion and exclusion criteria. Any disagreements between the two reviewers were resolved by discussion with a third reviewer (A.M.B.). Potential eligible studies were then assessed in full for inclusion according to eligibility criteria. Additionally, manual searches on the reference list of the selected articles were carried out for identification of additional studies. 
Table 1 search strategy

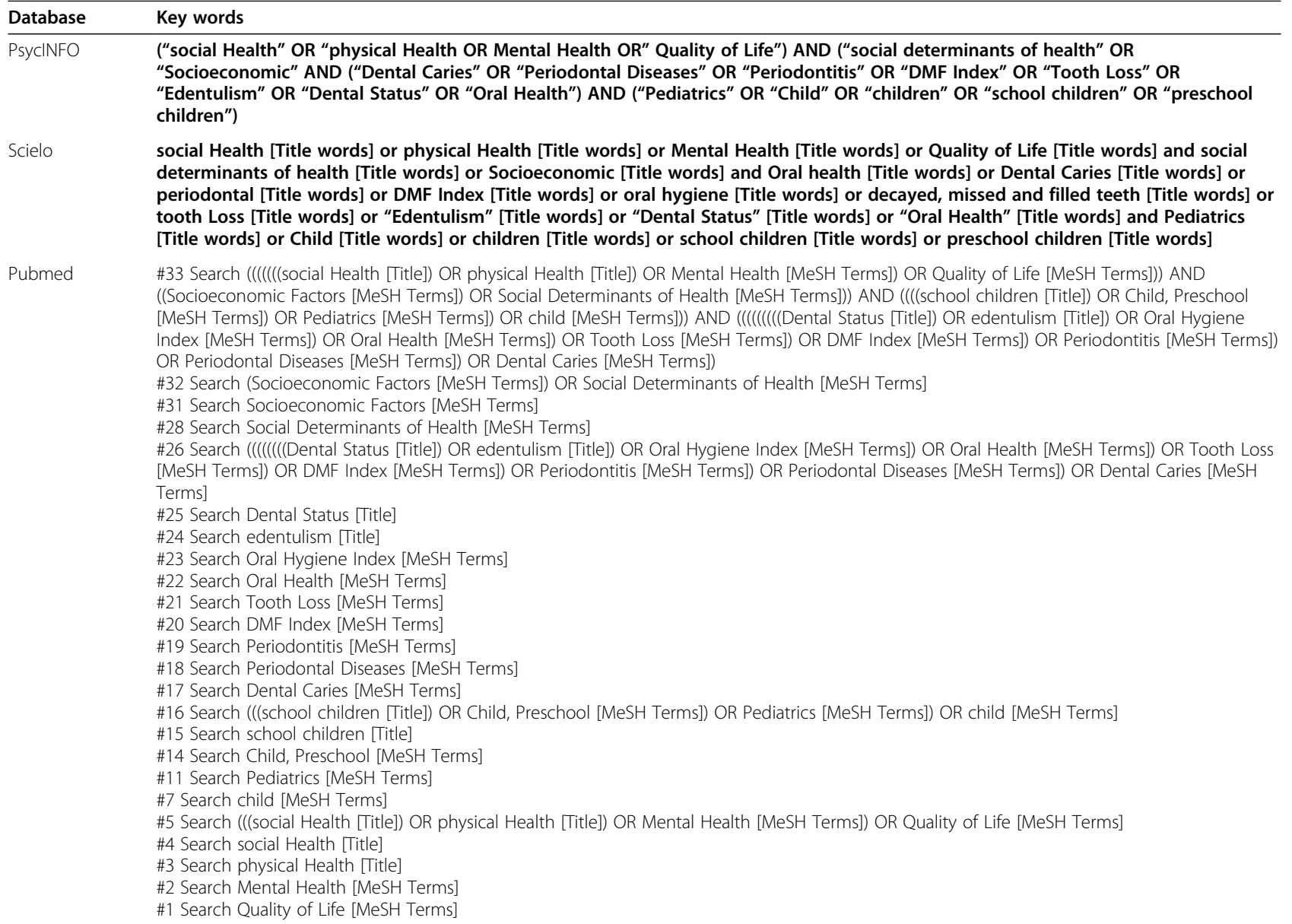

Scopus (TITLE-ABS-KEY (quality AND of AND life) OR TITLE-ABS-KEY (mental AND health) OR TITLE-ABS-KEY (physical AND health) OR TITLEABS-KEY (social AND health)) AND (TITLE-ABS-KEY (pregnant AND woman) OR TITLE-ABS-KEY (pregnancy) OR TITLE-ABS-KEY (mothers)) AND (TITLE-ABS-KEY (dental AND caries) OR TITLE-ABS-KEY (periodontal AND diseases) OR TITLE-ABS-KEY (periodontitis) OR TITLE-ABS-KEY (dmf AND index) OR TITLE-ABS-KEY (tooth AND loss) OR TITLE-ABS-KEY (oral AND health) OR TITLE-ABS-KEY (oral AND hygiene AND index) OR TITLE-ABS-KEY (edentulism) OR TITLE-ABS-KEY (dental AND status))

Web of $\quad$ TS $=$ (Quality of Life OR Health related Quality of Life OR Physical health OR mental health OR social health) AND TS $=$ (Dental Caries OR Knowledge $\quad$ Periodontal Diseases OR Periodontitis OR DMF Index OR Tooth Loss OR Edentulism OR Dental Status OR Oral Health OR Oral Hygiene Index) AND TS $=($ school children OR Preschool OR Pediatrics OR child $)$

Cochrane \#1 MeSH descriptor: [Quality of Life] explode all trees

\#2 MeSH descriptor: [Mental Health] explode all trees

\#3 (physical Health): ti,ab,kw

\#3 (social Health): ti,ab,kw

\#4 \#1 OR \#2 OR \#3

\#6 Search school children [Title]

\#7 Search Child, Preschool [MeSH Terms]

\#8 Search Pediatrics [MeSH Terms]

\#9 Search child [MeSH Terms]

Search (((school children [Title]) OR Child, Preschool [MeSH Terms]) OR Pediatrics [MeSH Terms]) OR child [MeSH Terms]

\#10 MeSH descriptor: [Dental Caries] explode all trees

\#11 MeSH descriptor: [Periodontal Diseases] explode all trees

\#12 MeSH descriptor: [Periodontitis] in all MeSH products

\#13MeSH descriptor: [DMF Index] explode all trees

\#14 MeSH descriptor: [Tooth Loss] explode all trees

\#15 ("edentulism"):ti,ab,kw

\#16 (Dental Status):tiab,kw

\#17 MeSH descriptor: [Oral Health] explode all trees

\#18 MeSH descriptor: [Oral Hygiene Index] explode all trees

\#18 \#9 OR \#10 OR \#11 OR \#12 OR \#13 OR \#14 OR \#15 OR \#16 OR \#17

\#19 \#4 AND \#8 AND \#18 


\section{Data extraction and quality assessment}

The following information was recorded from the selected articles: first author, year of publication, sample size, country, study design, and quality assessment. The authors of the selected papers were contacted to provide further details when necessary.

Five researchers recorded the data independently using predefined excel sheets. First, duplicated titles and abstracts of the selected papers were initially omitted after revision. Second, manuscripts were selected based on titles and abstracts for further review using the full texts. The duplicate papers were identified using "find duplicate" option on endnote software and were deleted. The selection of full text articles was conducted by 5 authors according to the eligibility criteria.

Disagreements between the researchers were resolved by discussion. The Unweighted Kappa used to assess the consistency between the two researchers (B.A. and A.B.) during the selection of studies was 0.86 .

\section{Quality assessment}

Quality assessment was performed by the same two researchers using the Critical Appraisal Checklist for observational studies proposed by The Joanna Briggs Institute (JBI) to assess the internal validity and risk of bias of the studies [31]. The checklist for cohort, casecontrol studies and cross-sectional studies are made of 10, 10 and 8 items, respectively. Each item may score one point for the answer "yes" of each study and the score may vary from 0 to 10 (cohort and case-control studies) or 0 to 8 (cross-sectional studies). The papers were categorized as follows: low quality (0-3 scores), medium quality (4-6 scores); and high quality (7-10 scores).

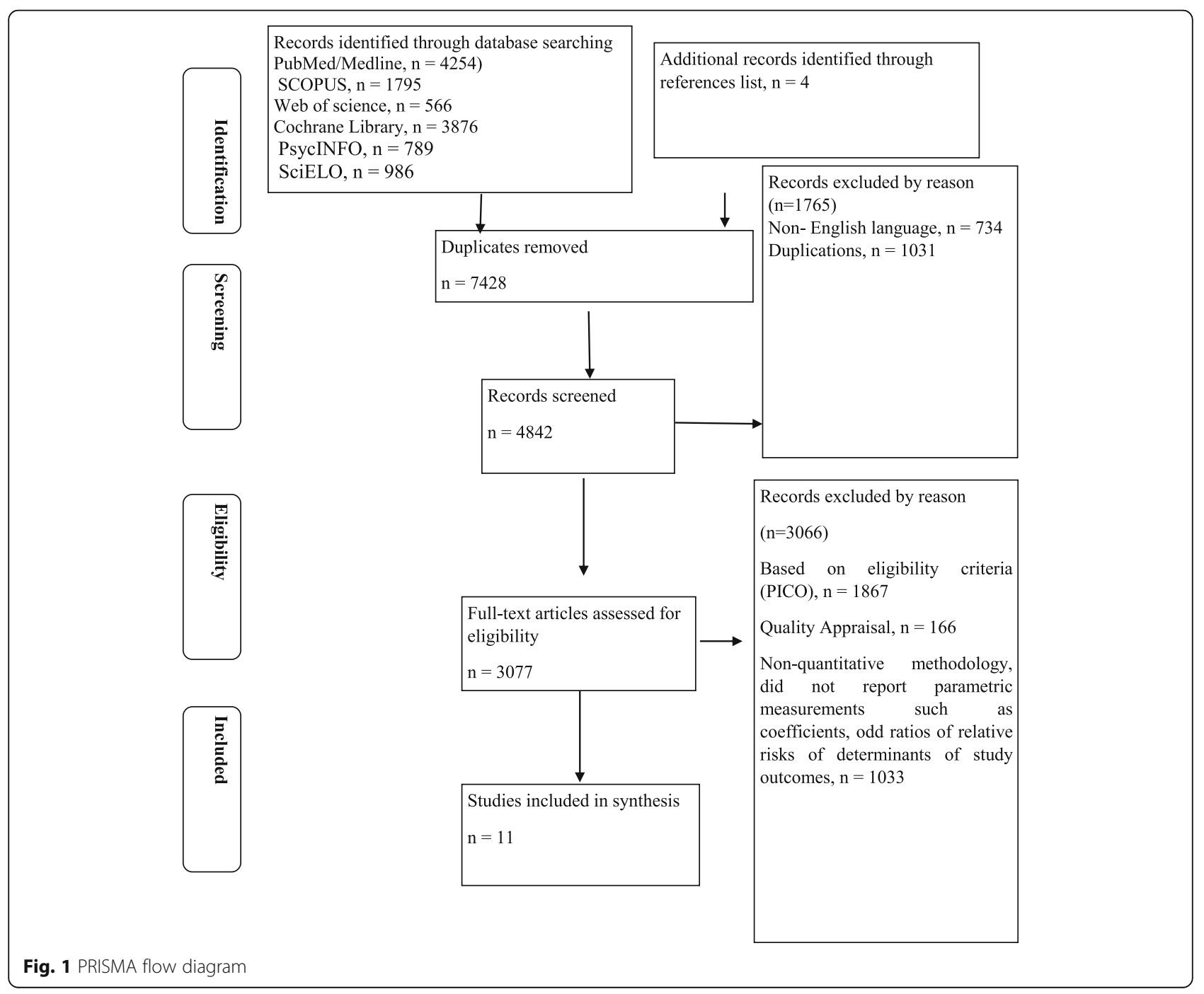


Data synthesis and statistical analysis

The meta-analysis was conducted to estimate pooled Odds Ratios (ORs) and 95\% confidence intervals (95\% $\mathrm{CI}$ ) on the relationship of oral health conditions, demographic and socioeconomic characteristics with OHRQoL in children. Heterogeneity between studies was assessed using $\mathrm{I}^{2}$ statistics that is percentage of variation studies [32]. According to $\mathrm{I}^{2}$ index Random and fixedeffect methods were used for estimation pooled effect size in defined subgroups [33]. When $\mathrm{I}^{2}$ indexed is lower than $50 \%$, the fixed effect model but if $\mathrm{I}^{2}$ index is higher than $50 \%$, random effect model used for estimation pooled effect size [33].

The trend of pooled ORs according to country's Human Development Index [34] (range $=0.761-0.939$ ), sample size (range $=260-1134$ ), year of study and age of participants (range $=3-12$ years) was calculated by cumulative regression analysis. HDI data was obtained from World Bank data [35]. Potential publication bias was tested using the rank correlation of Begg's test and Egger's test [36, 37]. Publication bias among studies was statistically significant $(P<0.05)$. Therefore, Meta Trim test was performed to estimate pooled OR to eliminate the publication bias. The level of significance established for all analyses was $5 \%(P \leq 0.05)$. Stata version 13.0 was used in all analyses (Stata Corporation, College Station, TX, USA).

\section{Results \\ Study selection}

Initially, 12,266 papers were identified through database searching and reference lists. Of them, 7428 studies were retained after removing duplicate references using "find duplicate" tool of endnote software. All titles and abstracts were reviewed, and 2586 were considered irrelevant and were excluded. The remaining 4842 articles were evaluated and further 1765 studies were excluded. The full text of the remaining 3077 articles was analysed for inclusion. Of them, 3066 studies were thereafter excluded according to the inclusion criteria. In the end, a total of 11 studies were included in this systematic review and meta-analysis [6, 38-47].

Figure 1 demonstrates the review process.

Table 2 Main characteristics of the studies selected

\begin{tabular}{|c|c|c|c|c|c|c|}
\hline author & participants & Sample size & year & country & design & Quality of the evidence \\
\hline [1] & Children & 510 & 2009 & Hong Kong & Case-control & Moderate \\
\hline [2] & Children & 286 & 2013 & Brazil & Cross-section & High \\
\hline [3] & Children & 784 & 2013 & Sri Lanka & Cross-section & Moderate \\
\hline [4] & Children & 103 & 2011 & New Zealand & Cohort & High \\
\hline$[5]$ & Children & 515 & 2012 & Brazil & Cross-section & Moderate \\
\hline [6] & Children & 815 & 2019 & Brazil & Cross-section & Moderate \\
\hline [7] & Children & 260 & 2011 & Brazil & Cross-section & High \\
\hline$[8]$ & Children & 638 & 2012 & Brazil & Cross-section & Moderate \\
\hline [9] & Children & 456 & 2017 & Brazil & Cross-section & High \\
\hline [10] & Children & 792 & 2010 & Brazil & Cross-section & High \\
\hline [11] & Children & 1134 & 2014 & Brazil & Cross-section & High \\
\hline
\end{tabular}

1. Du R, Yiu C, King N: Health-and oral health-related quality of life among preschool children with autism spectrum disorders. European Archives of Paediatric Dentistry 2019:1-9

2. de Paula JS, Leite ICG, de Almeida AB, Ambrosano GMB, Mialhe FL: The impact of socioenvironmental characteristics on domains of oral health-related quality of life in Brazilian schoolchildren. BMC oral health 2013, 13(1):10

3. Nanayakkara V, Renzaho A, Oldenburg B, Ekanayake L: Ethnic and socio-economic disparities in oral health outcomes and quality of life among Sri Lankan preschoolers: a cross-sectional study. International journal for equity in health 2013, 12(1):89

4. Shearer DM, Thomson WM, Broadbent JM, Poulton R: Does maternal oral health predict child oral health-related quality of life in adulthood? Health and quality of life outcomes 2011, 9(1):50

5. Paula JS, Leite IC, Almeida AB, Ambrosano GM, Pereira AC, Mialhe FL: The influence of oral health conditions, socioeconomic status and home environment factors on schoolchildren's self-perception of quality of life. Health and quality of life outcomes 2012, 10(1):6 6. Gatto RCJ, Garbin AJI, Corrente JE, Garbin CAS: The relationship between oral health-related quality of life, the need for orthodontic treatment and bullying, among Brazilian teenagers. Dental press journal of orthodontics 2019, 24(2):73-80

7. Abanto J, Carvalho TS, Mendes FM, Wanderley MT, Bönecker M, Raggio DP: Impact of oral diseases and disorders on oral health-related quality of life of preschool children. Community dentistry and oral epidemiology 2011, 39(2):105-114

8. Martins-Júnior P, Vieira-Andrade R, Corrêa-Faria P, Oliveira-Ferreira F, Marques L, Ramos-Jorge M: Impact of early childhood caries on the oral health-related quality of life of preschool children and their parents. Caries research 2013, 47(3):211-218

9. Chaffee BW, Rodrigues PH, Kramer PF, Vítolo MR, Feldens CA: Oral health-related quality-of-life scores differ by socioeconomic status and caries experience. Community dentistry and oral epidemiology 2017, 45(3):216-224

10. Piovesan C, Antunes JLF, Guedes RS, Ardenghi TM: Impact of socioeconomic and clinical factors on child oral health-related quality of life (COHRQoL). Quality of Life Research 2010, 19(9):1359-1366

11. Tomazoni F, Zanatta FB, Tuchtenhagen S, da Rosa GN, Del Fabro JP, Ardenghi TM: Association of gingivitis with child oral health-related quality of life. Journal of periodontology 2014, 85(11):1557-1565 


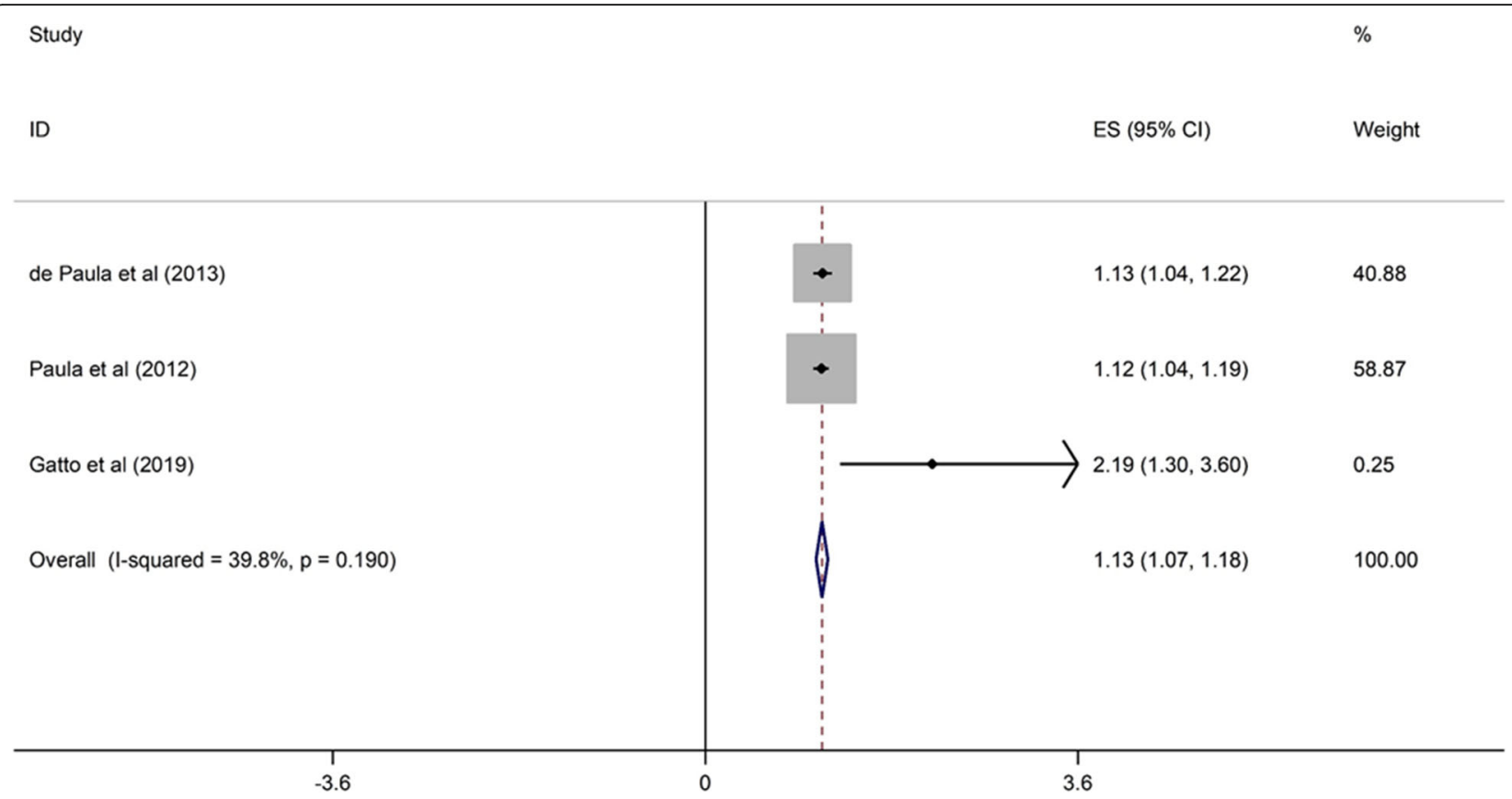

Fig. 2 Forest plot of effect of orthodontic treatment need on OHRQoL among children

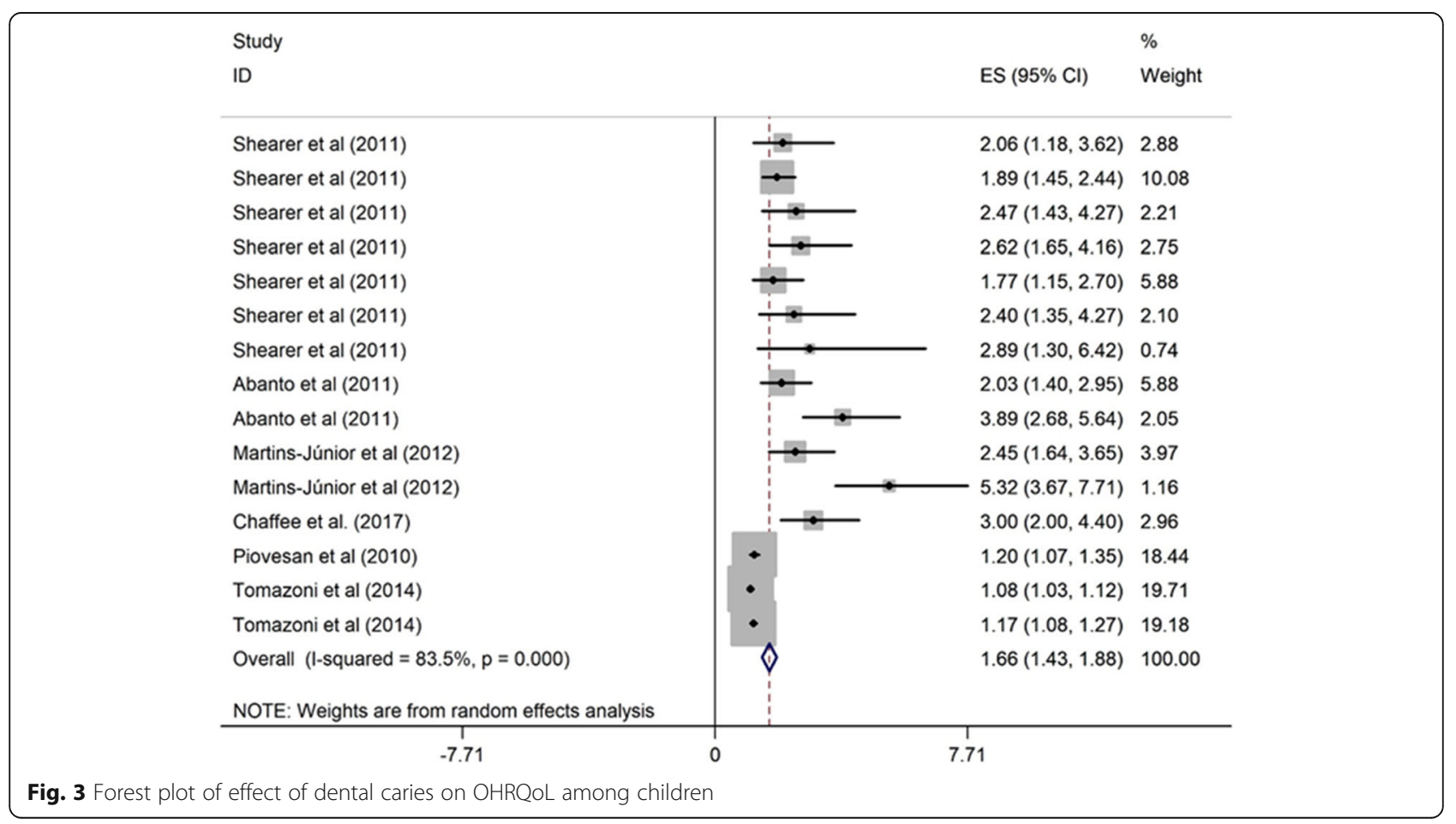




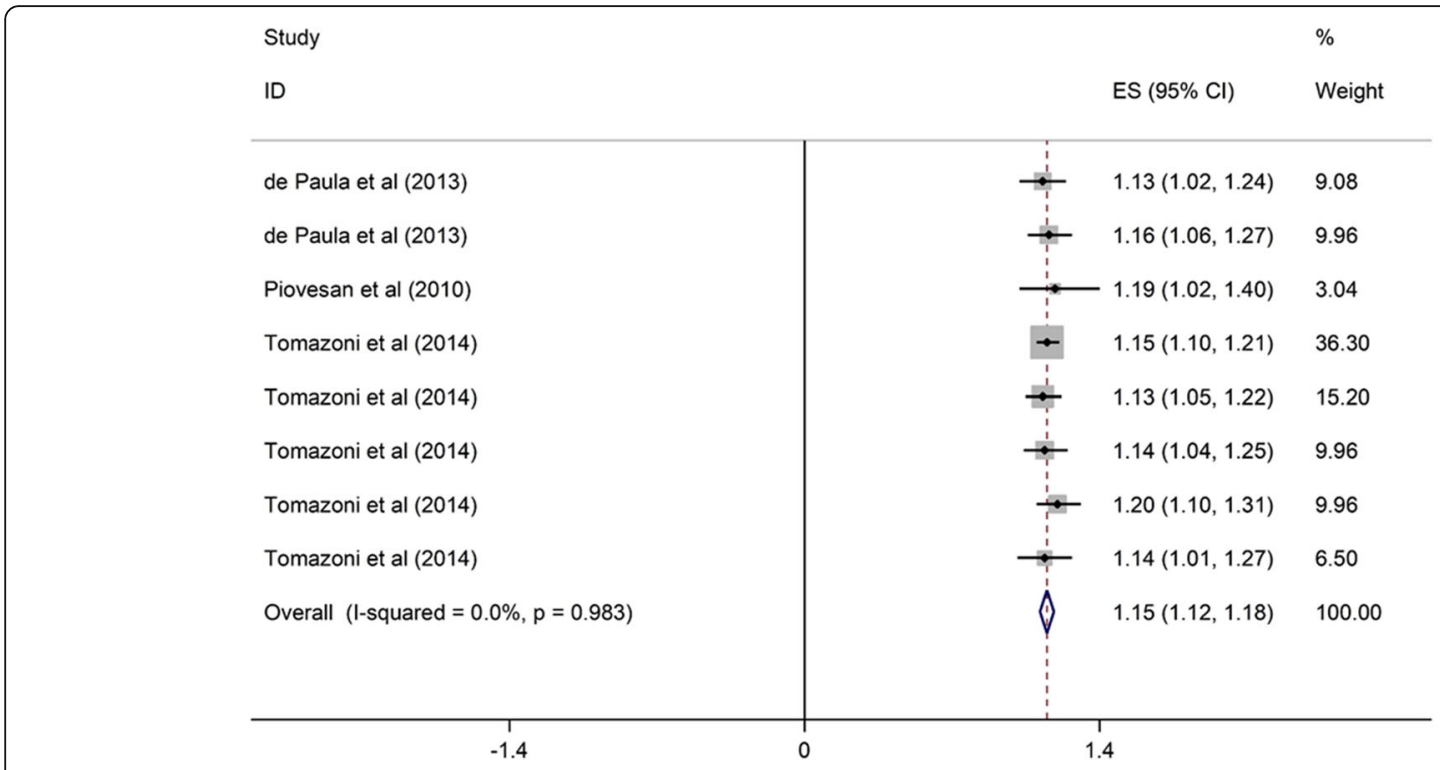

Fig. 4 Forest plot of effect of periodontal disease on OHRQOL among children

\section{Study characteristics}

The characteristics of the 11 selected studies are presented in Table 2. The sample size ranged from 103 to 1134 participants. Most studies were published between 2009 and 2013 and they predominantly conducted in Brazil. One cohort, one case-control and 9 cross-sectional studies were selected. Of the 11 studies, 6 were considered of high quality.

\section{Meta-analysis}

Oral health status and OHRQoL

Orthodontic treatment need and OHRQoL Three crosssectional studies evaluated the relationship between orthodontic treatment need and OHRQoL among children $[6,39,42]$. All studies were conducted in upper middleincome countries between 2012 and 2019. The sample size ranged from 286 to 815 and two studies were of high quality. Children with orthodontic treatment need had 13\% higher probability of poor OHRQoL than those without orthodontic treatment need $(\mathrm{OR}=1.13,95 \% \mathrm{CI}=1.07,1.18)$ (Fig. 2).

Dental caries and OHRQoL The relationship between dental caries and OHRQoL in children was assessed in six studies [41, 43-47]. Of them, five studies were crosssectional design [43-47], and one used cohort design

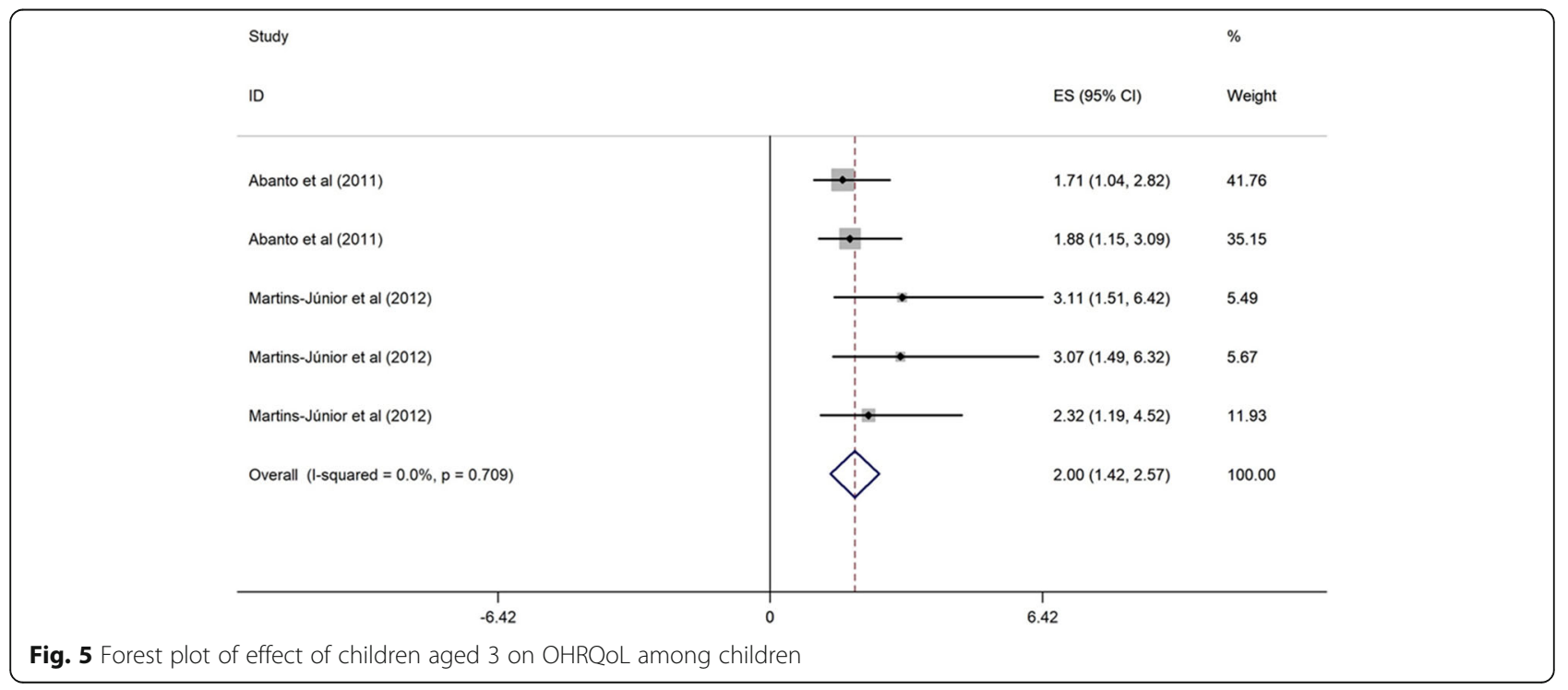




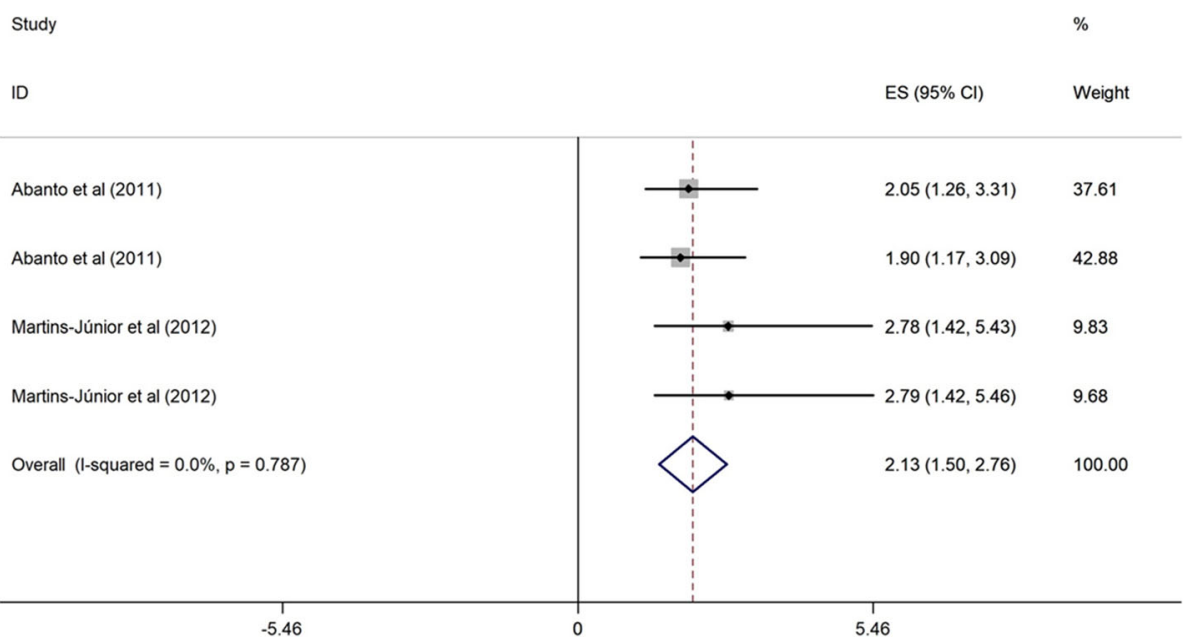

Fig. 6 Forest plot of effect of children aged 4 on OHRQoL among children

[41]. Five studies were carried out in upper middleincome country $[6,39,40,45,47]$ and one was conducted in higher-income country [41]. The studies were published from 2011 to 2017, and the sample size ranged from 260 to 1134 . Three studies were of high quality and the other three were of moderate quality. Higher levels of dental caries was associated with poor OHRQoL. Children with more dental caries were 1.66 times more likely to have poor OHRQoL than cariesfree children $(\mathrm{OR}=1.66,95 \% \mathrm{CI}=1.43,1.88)(\mathrm{Fig} .3)$.

Periodontal disease and OHRQoL Three crosssectional studies conducted in upper middle-income countries assessed the association between periodontal disease and OHRQoL among children [39, 46, 47]. They were published from 2010 to 2014, and the sample size ranged from 286 to 1134. All three studies of high quality. Periodontal disease was significantly associated with poor OHRQoL in children $(\mathrm{OR}=1.15,95 \% \mathrm{CI}=1.12$, 1.18) (Fig. 4).

\section{Demographic and socioeconomic characteristics}

Children's age and OHRQoL among children Two cross-sectional studies conducted in upper middleincome evaluated the association between low children's age (3-5 years vs. $>5$ years) and OHRQoL [43, 44]. These studies were published from 2011 to 2012, and the sample size ranged from 260 to 638 . The two studies were of high quality, and one research was categorized as poor quality. Children aged 3, 4 and 5 years were 2.00 , 2.13 and 3.68 times more likely to have poor OHRQoL $(\mathrm{OR}=2.00,95 \% \mathrm{CI}=1.42,2.57 ; \mathrm{OR}=2.13,95 \% \mathrm{CI}=$ $1.50,2.76$; and $\mathrm{OR}=3.68,95 \% \mathrm{CI}=2.20,5.17$ ) than children with 5 years-old (Figs. 5, 6 and 7).

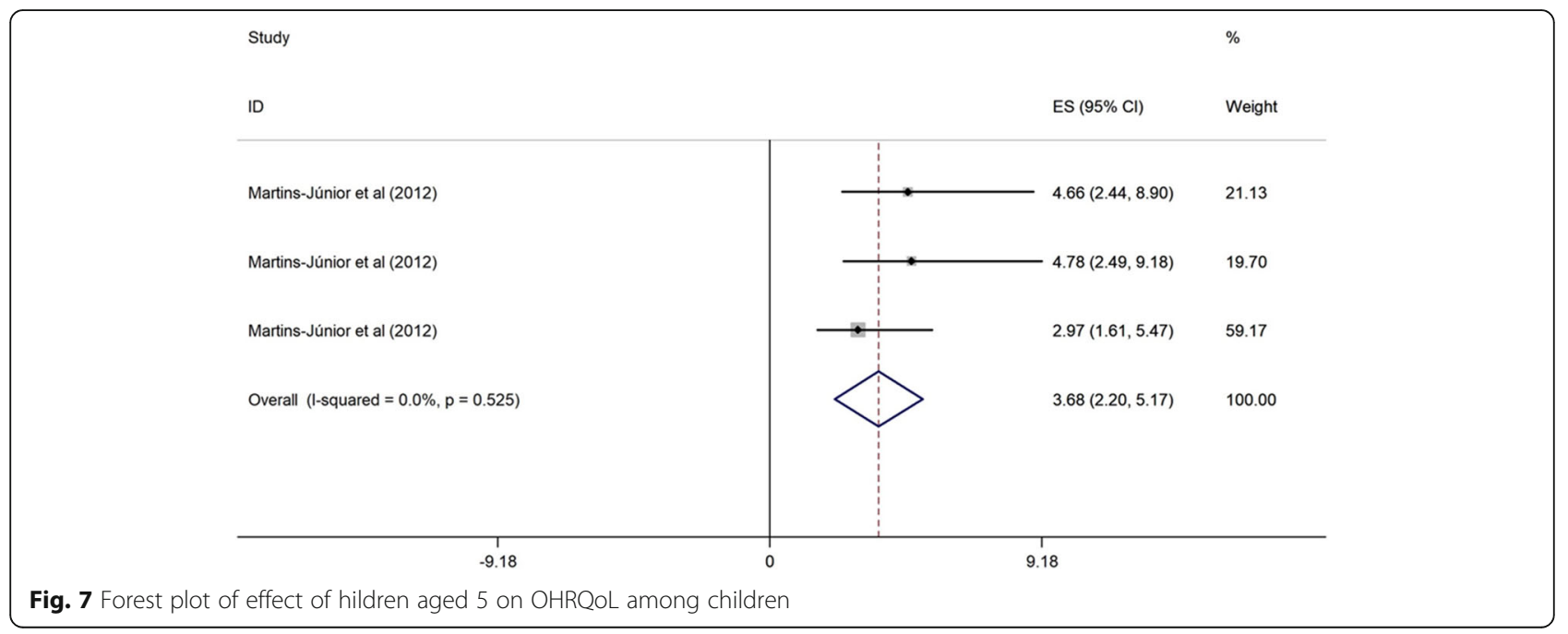




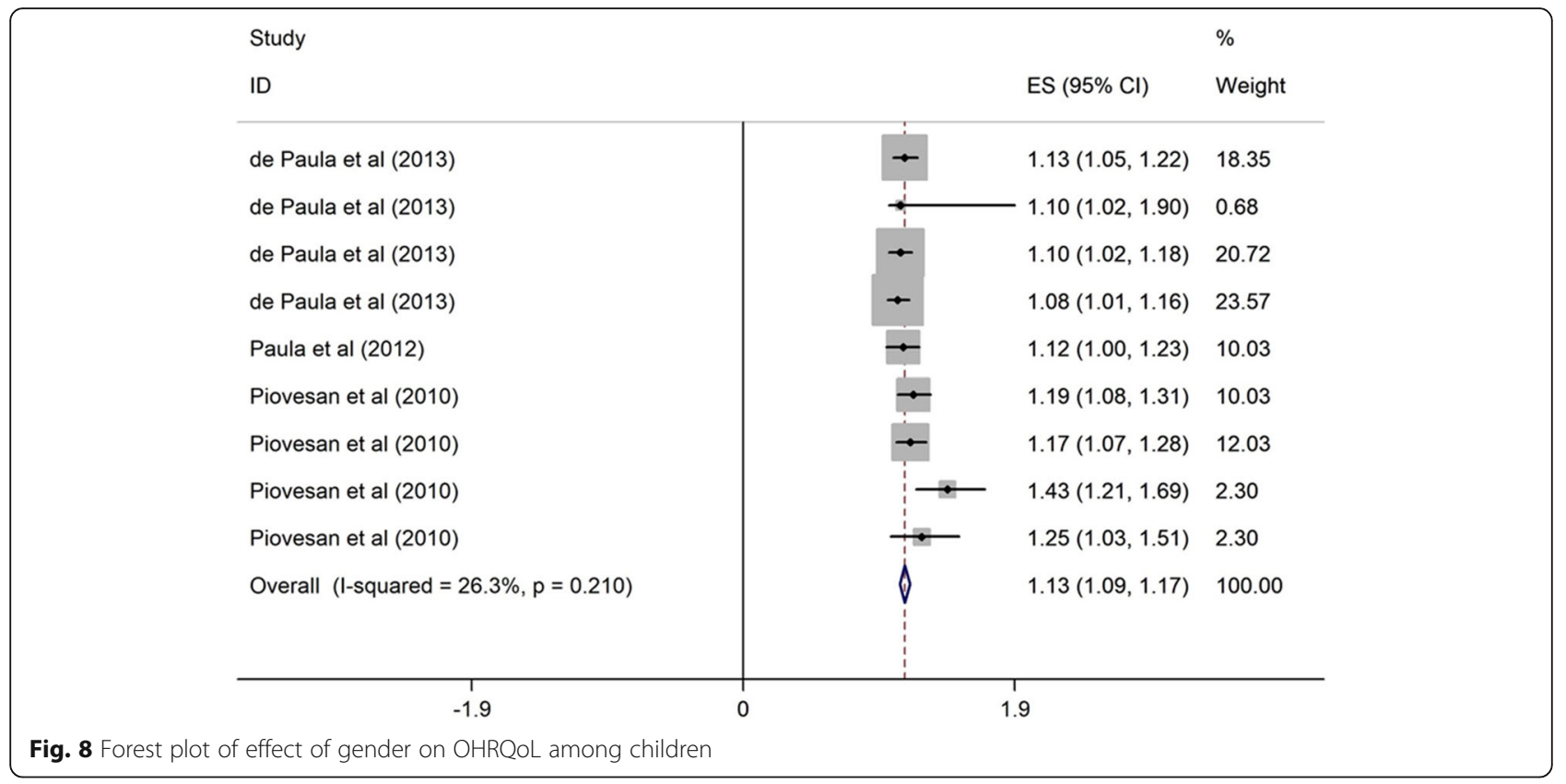

Gender and OHRQoL Three cross-sectional studies conducted in upper middle-income countries [6, 39, 46] examined the association between gender and OHRQoL among children. The studies were published from 2010 to 2013 , and the sample size ranged from 286 to 792 . Two studies had high quality. There was a positive association between gender (girls vs. boys) and poor OHRQoL among children. Female children were 1.14 times more likely to have poor OHRQoL than male children $(\mathrm{OR}=1.13,95 \% \mathrm{CI}=1.09,1.17)$ (Fig. 8).

Family income and OHRQoL Four cross-sectional studies carried out in upper middle-income countries (Brazil) evaluated the relationship between family income and OHRQoL among children. These studies were conducted between 2010 to 2014, and the sample sizes

Study
ID
de Paula et al (2013)
de Paula et al (2013)
de Paula et al (2013)
de Paula et al (2013)
Paula et al (2012)
Piovesan et al (2010)
Tomazoni et al (2014)
Tomazoni et al (2014)
Overall (I-squared $=51.1 \%, \mathrm{p}=0.046)$
NOTE: Weights are from random effects analysis

Fig. 9 Forest plot of effect of family income on OHRQOL among children 
ranged from 286 to 1134 with a high-quality structured approach. All studies considered the threshold of $\$ 70$ per month to classify the participants as low- $(<\$ 70)$ and high-family income $(\geq \$ 70)$. Children from low-income families $(<70 \$)$ were 1.16 times more likely to have poor OHRQoL (OR $=1.16,95 \% \mathrm{CI}=1.11,1.21)$ (Fig. 9).

Maternal education and OHRQoL Four crosssectional studies [6, 40, 46, 47] carried out in upper middle-income countries evaluated the association between maternal education and OHRQoL among children. The studies were published from 2010 to 2014, and the sample size ranged from 515 to 1134. Three studies were considered of high quality. Lower maternal education ( $\leq 6$ years of schooling) was significantly associated with poor OHRQoL $(\mathrm{OR}=1.12,95 \% \mathrm{CI}=1.00$, 1.23) (Fig. 10).

Assessment of heterogeneity Heterogeneity between studies was observed on the meta-analysis of dental caries (I2 $=83.5 \%, P<0.001)$, family income $(\mathrm{I} 2=51.1 \%$, $P=0.046)$ and maternal education $(\mathrm{I} 2=89.2 \%, P<0.001)$ with OHRQoL. The meta regression analysis showed that country's HDI $(C=1.45, p$ value $=0.03)$, study's sample size $(C=2.32, p$ value $<0.001)$, year of study $(\mathrm{C}=1.48, p$ value $<0.001)$ and age of children $(\mathrm{C}=1.57$, $p$ value $<0.001)$ were significant characteristics that influenced the observed heterogeneities (Fig. 11).

Publication bias Begg's test and Egger's tests showed evidence of publication bias (Begg's test: $P<0.001$; Egger's test: $P<0.001)$ (Fig. 12). According to publication bias test, a significant publication bias among studies was noted $(\mathrm{C}=2.38 ; P$-value $=0.001)$ (Fig. 12). Therefore, metatrim analysis was performed in order to remove the effect of publication bias on the pooled OR. The meta-trim analysis revolved that the pooled OR $0.17(95 \% \mathrm{CI}, 0.13-0.21)$ in the random effect model (Fig. 13).

\section{Discussion}

This study aimed to examine the possible relationship of oral health conditions, demographics and socioeconomic characteristics with OHRQoL in children.

Our findings suggest that poor oral health status, greater age, female gender and worse socioeconomic status were significantly associated with poor OHRQoL. These results are in accordance with previous research $[43,48,49]$ that showed a correlation between socioeconomic status, clinical status and OHRQoL in preschool children $[25,43]$. In this study, children's poor OHRQoL was strongly correlated with lower levels of maternal education ( $\leq$ grade 6 ). Piovesan et al. suggested that low household income was a risk factor for poor OHRQoL in children [46]. Besides, lower paternal and maternal educational level were associated with poor OHQoL of their children [46]. Female gender was also associated with poor OHRQoL, which is in agreement with previous studies $[39,46]$. The possible explanation for this finding is the poor self-esteem and poor selfperception of oral health and body image among girls compared with boys [50-52]. According to Honkala et al. [53], female gender is significantly correlated with frequency of tooth brushing, and self-esteem among schoolchildren was also associated with a high socioeconomic status of the family. Foster Page et al. [52]

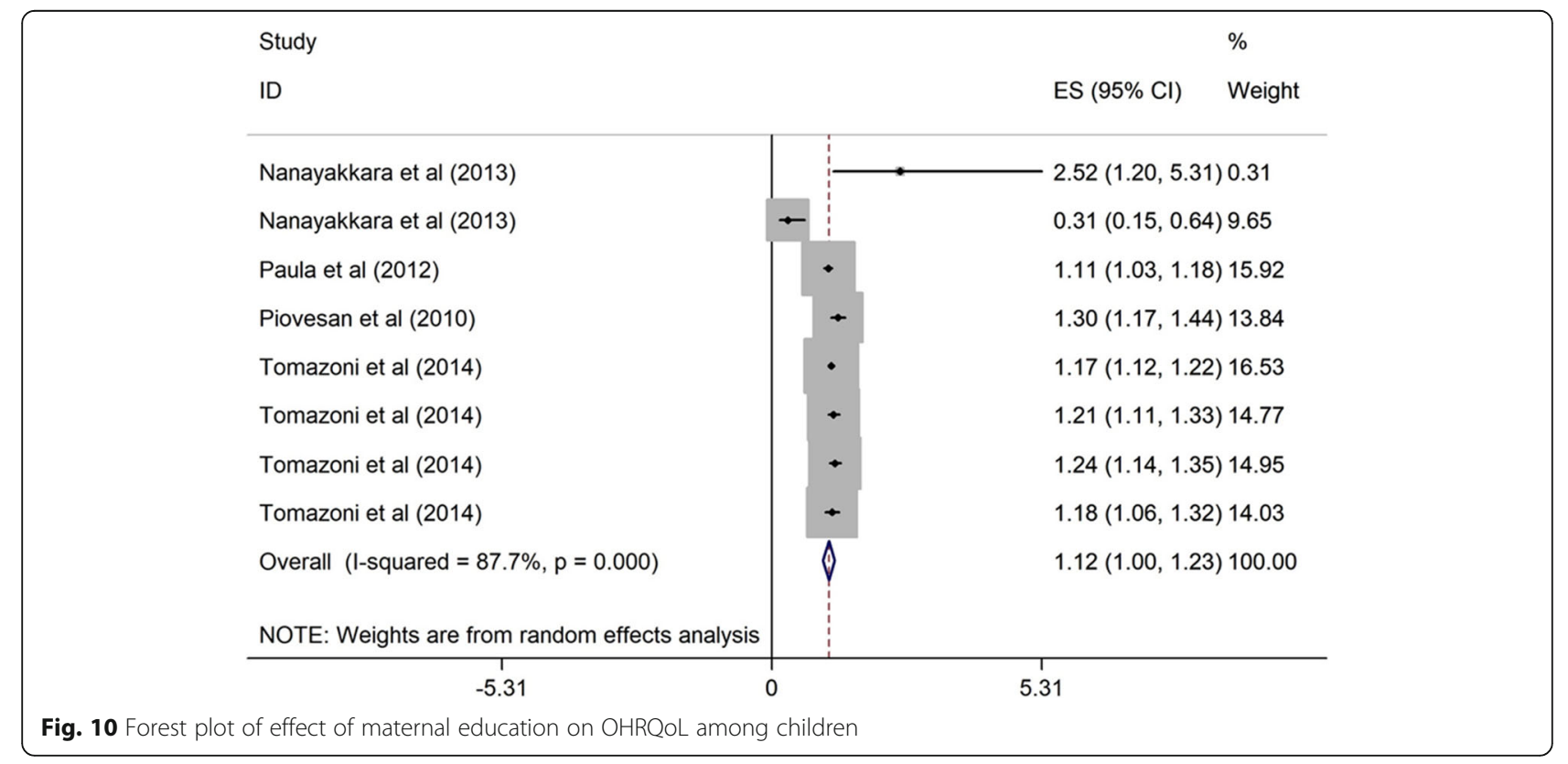




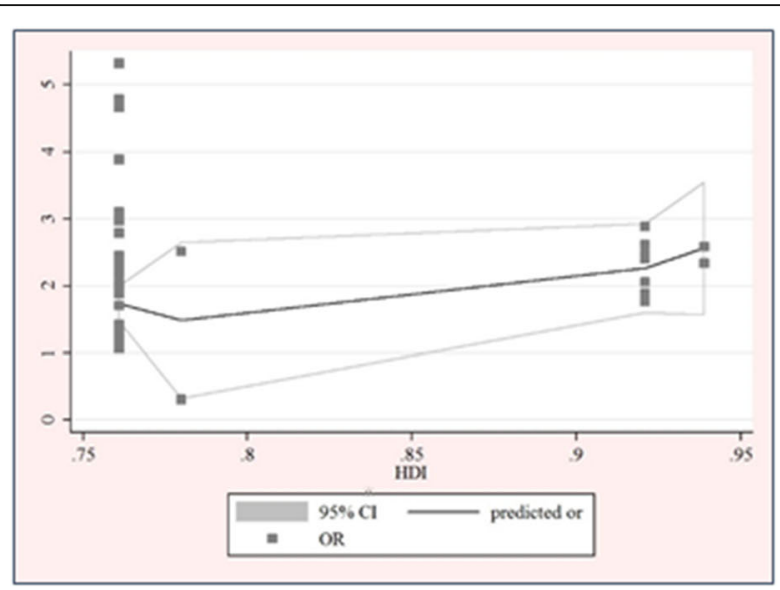

A

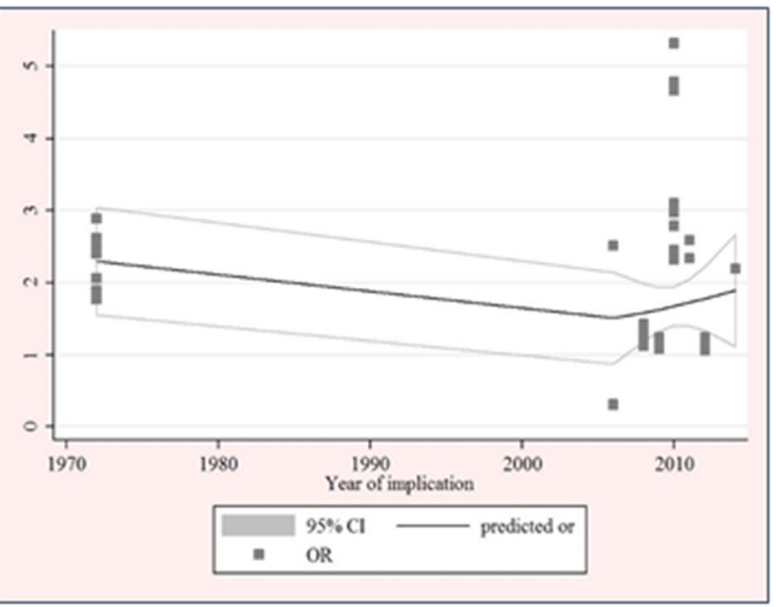

C

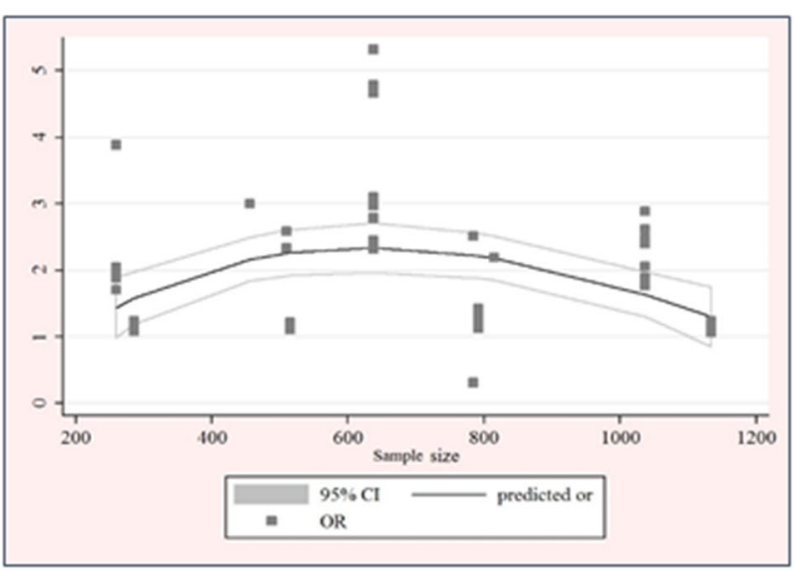

B

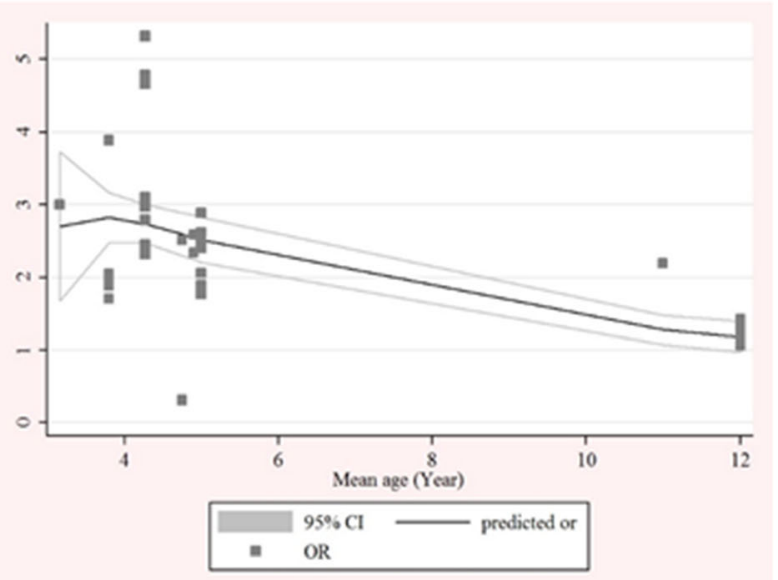

D

Fig. 11 Meta-regression analysis for determine association between poor quality of life with HDI (a), sample size (b) and year of implication (c), children age (d)
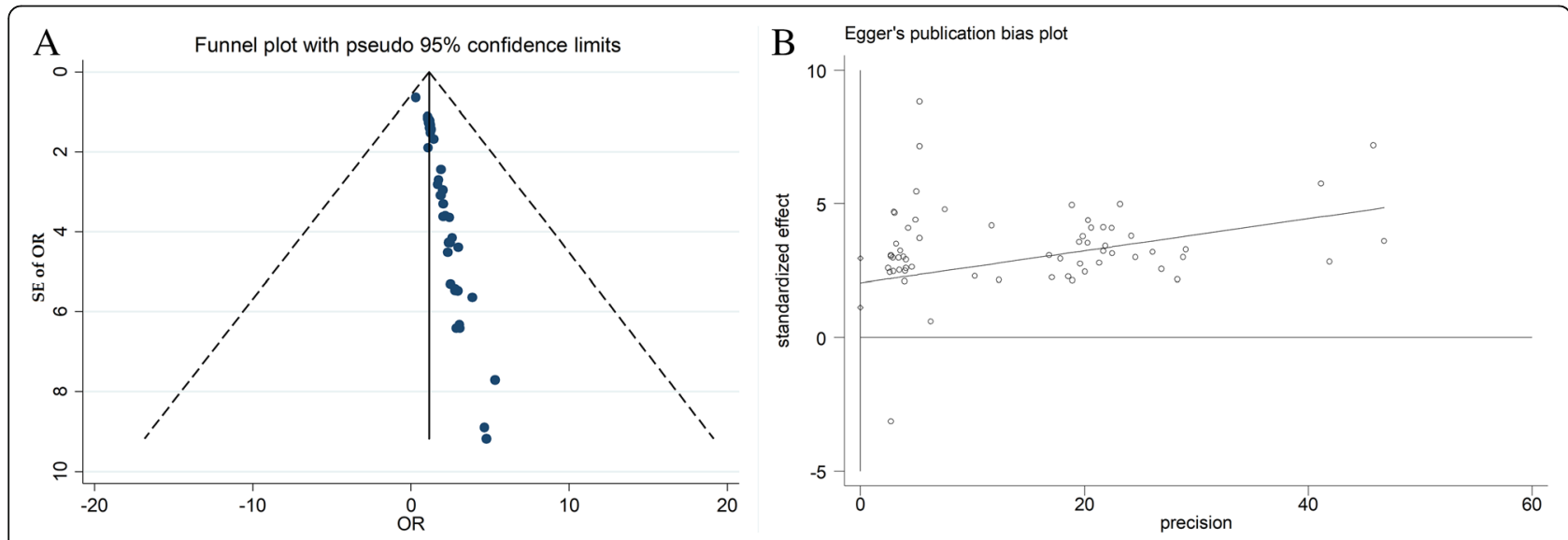

Fig. 12 Determine publication bias by Beggs (a) and Egger's (b) tests 


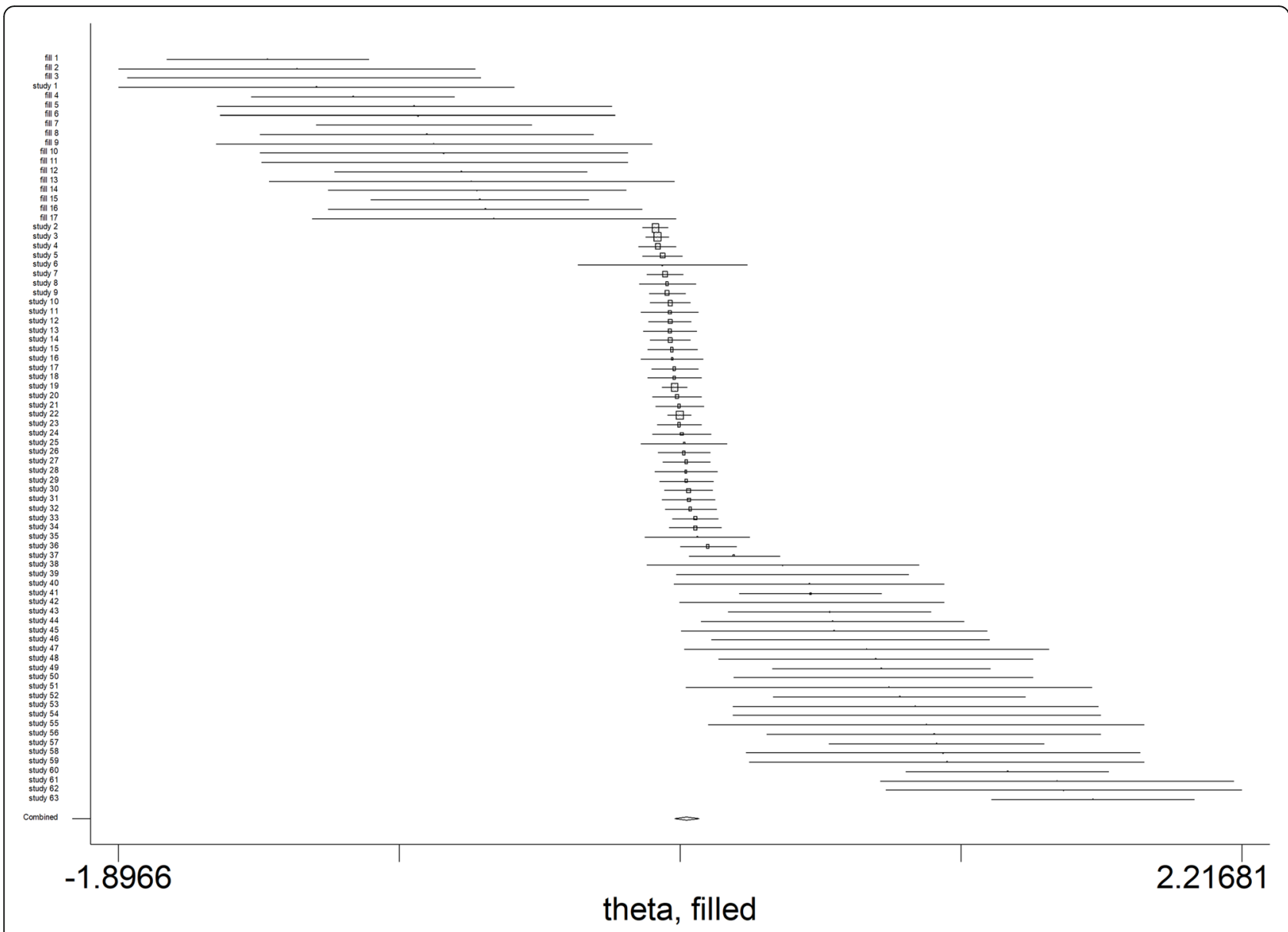

Fig. 13 Meta trim plot for determine pooled OR without publication bias

reported that gender's psychosocial characteristics can affect OHRQoL.

Moreover, a negative association between orthodontic treatment need and function limitation dimension of CPQ11-14 was reported. Functional limitation is composed of three items that assesses difficulty in eating and eating hot and cold foods; taken longer to eat a meal; difficulty in biting or chewing firm foods (e.g. apples, corn on the cob, steak); difficulty in opening the mouth wide; problems with pronouncing some words; difficulty with eating favorite foods; difficulty with drinking through a straw [50,51]. Another research revealed that orthodontic treatment need was associated with poor OHRQoL and dental aesthetics [50].

Bleeding was also significantly related to emotional and social well-being domains of the CPQ11-14. These findings are consistent with those reported by Lopez and Baelum [54] on the association between periodontal disease and poor OHRQoL. Nevertheless, a different OHRQoL instrument (Oral Health Impact Profile OHIP) was used to assess the impact of periodontal diseases on OHRQoL.
Previous studies suggested the poor correlation between dental caries and oral symptoms and functional limitations domains of CPQ $[6,55]$. Furthermore, orthodontic treatment need was the only clinical variable associated with OHRQoL [46, 56]. As a result, the orthodontic treatment need was mediated by the individual and socio environmental characteristics.

The reported data highlight the possible significant impact of social interventions and health promotion strategies. Such interventions could be beneficial to support the development of supportive environments for this population. They can also improve their health-related skills to enhance their health status and to decrease health inequalities $[4,25,46]$. Oral symptoms and functional limitations had the most significant impact on oral health conditions in terms of adolescents' social relationships. (Agou et al.) [51]. According to Marmot and Bell, tackling the social determinants of health, including improving individual living status and structural drivers (e.g. laws, policies, economic conditions and cultural norms that shape and influence patterns of behaviour and individual capacities) are paramount. Furthermore, 
socio-environmental characteristics significantly affected children's daily living status $[57,58]$. As a result, promoting health status should be conducted for planning health promotion interventions in all social environments in which children live their lives, in order to promote supportive environments for them [59]. Policymakers of the health sector should address oral health at population level by reducing social inequalities.

\section{Limitations}

This study has limitations that should be acknowledged. First, the included studies assessed OHRQoL using different questionnaires. Second, OHRQoL instruments might be considered generic questionnaires to assess the relationship between dental clinical measures and children's OHRQoL, including periodontal disease. Third, articles published in non-English languages were excluded, which may have influence our results. Fourth, the selected articles investigated different predictors of OHRQoL and have used distinct analytical approaches, including univariate and multivariable regression methods. In addition, the categories of the predictors varied significantly between the selected papers, such as those employed to assess maternal education and family income. Therefore, specific inclusion criteria were necessary to include studies with similar methodological approaches in order to perform the meta-analysis. Fifth, some of the papers initially selected were thereafter excluded due to lack of information, as the corresponding author of those articles did not reply our contact to provide the information needed, such as the measures of association (e.g. odds ratio). Finally, the included studies did not inform the validity of the OHRQoL instruments.

\section{Conclusion}

In conclusion, socioeconomic conditions, demographic characteristics and dental clinical measures might differently affect oral health-related quality of life among children. Our findings suggest that children aged 3-5 years, female children, those whose families earned less than 70 dollars per month, whose mothers had low education were more likely to poor OHRQoL. In addition, orthodontic treatment need, dental caries and periodontal disease were significantly associated with poor OHRQoL in children.

Considering the need to design and develop oral health strategies to improve children's oral health, social and environmental conditions where the children live should be considered in planning, implementation and evaluation of oral health promotion activities. Also, further longitudinal studies should be conducted to determine causal relationships between the investigated predictors and OHRQoL.

\section{Abbreviations}

QoL: Quality of life; DMFT: Decayed, missing and filled teeth; OHRQoL: Oral health-related quality of life; PRISMA: Preferred for systematic reviews and meta-analyses; PPD: Pocket probing depth; CAL: Clinical attachment level; JBI: The Joanna Briggs institute; OR: Odds ratio; Cl: Confidence interval; PSI: Periodontal screening index; BOP: Bleeding on probing; TD: Tooth decay; ECOHIS: Early childhood oral health impact scale; MT: Missing teeth

\section{Acknowledgments}

The authors would like to acknowledge the contributions of Mehdi Noroozi to the work of this review of evidence.

\section{Authors' contributions}

Study design: BA and AB. Database searched, data extraction and data synthesis: BA, AHB, and YF. Initial manuscript draft: BA, EA, and AHB. Critical revision of the manuscript: YF, MW, M H, AB and LFM. All authors read and approved the final version of the manuscript.

\section{Funding}

This research did not receive any specific grant from funding agencies in the public, commercial, or not -for -profit sectors. The funders had no role in

study design, data collection and analysis, decision to publish, or preparation of the manuscript.

\section{Availability of data and materials}

The datasets used and/or analyzed during the current study are available from the corresponding author on reasonable request.

Ethics approval and consent to participate

Not Applicable.

\section{Consent for publication}

Not applicable.

\section{Competing interests}

The authors declare that they have no competing interests.

\section{Author details}

${ }^{1}$ Department of nursing, faculty of nursing and midwifery, Tehran medical sciences, Islamic Azad University, Tehran, Iran. ${ }^{2}$ Department of Social and Preventive Dentistry, Dental School, Federal University of Minas Gerais, Belo Horizonte, Brazil. ${ }^{3}$ Student Research Committee, School of Allied Medical Sciences, Shahid Beheshti University of Medical Sciences, Tehran, Iran. ${ }^{4}$ Social Determinants of Health Research Center, Saveh University of Medical Sciences, Saveh, Iran. ${ }^{5}$ Substance Abuse and Dependence Research Center, University of Social Welfare and Rehabilitation Sciences, Tehran, Iran.

${ }^{6}$ Department of Environmental Health Engineering, Hormozgan University of Medical Sciences, Bandar Abbas, Iran.

Received: 11 February 2020 Accepted: 6 October 2020

Published online: 22 October 2020

\section{References}

1. Sischo L, Broder H. Oral health-related quality of life: what, why, how, and future implications. J Dent Res. 2011;90(11):1264-70.

2. Mohammadi Gharehghani MA, Bayani A, Bayat A-H, Hemmat M, Karimy M, Ahounbar E, Armoon B, Fakhri Y, Schroth RJ: Poor Oral Health-Related Quality of Life among Pregnant Women: A Systematic Review and MetaAnalysis. International Journal of Dental Hygiene, $\mathrm{n} / \mathrm{a}(\mathrm{n} / \mathrm{a})$.

3. Locker D, Allen F. What do measures of 'oral health-related quality of life'measure? Community Dent Oral Epidemiol. 2007;35(6):401-11.

4. Gerritsen AE, Allen PF, Witter DJ, Bronkhorst EM, Creugers NH. Tooth loss and oral health-related quality of life: a systematic review and meta-analysis. Health Qual Life Outcomes. 2010;8(1):126.

5. Rebelo MAB, Rebelo Vieira JM, Pereira JV, Quadros LN, Vettore MV. Does oral health influence school performance and school attendance? A systematic review and meta-analysis. Int J Paediatr Dent. 2019;29(2):138-48.

6. Paula JS, Leite IC, Almeida AB, Ambrosano GM, Pereira AC, Mialhe FL. The influence of oral health conditions, socioeconomic status and home environment factors on schoolchildren's self-perception of quality of life. Health Qual Life Outcomes. 2012;10(1):6. 
7. Fisher-Owens SA, Gansky SA, Platt LJ, Weintraub JA, Soobader M-J, Bramlett MD, Newacheck PW. Influences on children\&\#039;s oral health: a conceptual model. Pediatrics. 2007;120(3):e510.

8. Mignogna M, Fedele S. The neglected global burden of chronic oral diseases. J Dent Res. 2006;85(Suppl 5):390-1.

9. Low W, Tan S, Schwartz S. The effect of severe caries on the quality of life in young children. Pediatr Dent. 1999;21(6):325-6.

10. Steele JG, Sanders AE, Slade GD, Allen PF, Lahti S, Nuttall N, Spencer AJ. How do age and tooth loss affect oral health impacts and quality of life? A study comparing two national samples. Community Dent Oral Epidemiol. 2004;32(2):107-14

11. Mason J, Pearce MS, Walls AWG, Parker L, Steele JG. How Do factors at different stages of the Lifecourse contribute to Oral-health-related quality of life in middle age for men and women? J Dent Res. 2006;85(3):257-61.

12. Lawrence HP, Thomson WM, Broadbent JM, Poulton R. Oral health-related quality of life in a birth cohort of 32-year olds. Community Dent Oral Epidemiol. 2008:36(4):305-16.

13. Sanders AE, Slade GD, Lim S, Reisine ST. Impact of oral disease on quality of life in the US and Australian populations. Community Dent Oral Epidemiol. 2009;37(2):171-81.

14. McGrath C, Bedi R. A study of the impact of oral health on the quality of life of older people in the UK- findings from a national survey. Gerodontology. 1998;15(2):93-8.

15. Slade GD, Nuttall N, Sanders AE, Steele JG, Allen PF, Lahti S. Impacts of ora disorders in the United Kingdom and Australia. Br Dent J. 2005;198(8):48993

16. Slade GD, Spencer AJ, Locker D, Hunt RJ, Strauss RP, Beck JD. Variations in the social impact of Oral conditions among older adults in South Australia, Ontario, and North Carolina. J Dent Res. 1996;75(7):1439-50.

17. Sanders AE, Spencer AJ. Childhood circumstances, psychosocial factors and the social impact of adult oral health. Community Dent Oral Epidemiol. 2005;33(5):370-7.

18. Baker SR, Mat A, Robinson PG. What psychosocial factors influence adolescents' Oral health? J Dent Res. 2010;89(11):1230-5.

19. Sanaei Nasab H, Yazdanian M, Mokhayeri Y, Latifi M, Niksadat N, Harooni J, Armoon B. The role of psychological theories in oral health interventions: a systematic review and meta-analysis. Int J Dent Hyg. 2019;17(2):142-52.

20. Locker D, Jokovic A, Tompson B, Prakash P. Is the child perceptions questionnaire for 11-14 year olds sensitive to clinical and self-perceived variations in orthodontic status? Community Dent Oral Epidemiol. 2007; 35(3):179-85.

21. Barbosa T, Gavião M. Oral health-related quality of life in children: part II. Effects of clinical oral health status. A systematic review. Int J Dent Hyg. 2008;6(2):100-7.

22. Bendo CB, Paiva SM, Torres CS, Oliveira AC, Goursand D, Pordeus IA, Vale MP. Association between treated/untreated traumatic dental injuries and impact on quality of life of Brazilian schoolchildren. Health Qual Life Outcomes. 2010;8(1):114.

23. Gherunpong S, Tsakos $G$, Sheiham A. The prevalence and severity of oral impacts on daily performances in Thai primary school children. Health Qual Life Outcomes. 2004:2(1):57.

24. Jokovic A, Locker D, Guyatt G. Short forms of the child perceptions questionnaire for 11-14-year-old children (CPQ11-14): development and initial evaluation. Health Qual Life Outcomes. 2006;4(1):4.

25. Locker D. Disparities in oral health-related quality of life in a population of Canadian children. Community Dent Oral Epidemiol. 2007;35(5):348-56.

26. Edelstein BL. Disparities in Oral health and access to care: findings of National Surveys. Ambul Pediatr. 2002;2(2):141-7.

27. Ghaffari M, Rakhshanderou S, Ramezankhani A, Buunk-Werkhoven Y, Noroozi M, Armoon B. Are educating and promoting interventions effective in oral health?: a systematic review. Int J Dent Hyg. 2018;16(1):48-58.

28. Ghaffari M, Rakhshanderou S, Ramezankhani A, Noroozi M, Armoon B. Oral health education and promotion programmes: meta-analysis of 17-year intervention. Int J Dent Hyg. 2018;16(1):59-67.

29. Do L, Roberts-Thomson K: Dental caries experience in the Australian adult population. 2007.

30. Peterson J, Welch V, Losos M, Tugwell P. The Newcastle-Ottawa scale (NOS) for assessing the quality of nonrandomised studies in meta-analyses. Ottawa: Ottawa Hospital Research Institute; 2011.
31. Moola S MZ, Tufanaru C, Aromataris E, Sears K, Sfetcu R, Currie M, Qureshi R, Mattis P, Lisy K, Mu P-F. :Chapter 7: Systematic reviews of etiology and risk: The Joanna Briggs Institute https://reviewersmanual.joannabriggs.org/; 2017.

32. Langan D, Higgins JP, Jackson D, Bowden J, Veroniki AA, Kontopantelis E, Viechtbauer W, Simmonds M. A comparison of heterogeneity variance estimators in simulated random-effects meta-analyses. Res Synth Methods. 2019;10(1):83-98.

33. Higgins JP, Thompson SG. Quantifying heterogeneity in a meta-analysis. Stat Med. 2002;21(11):1539-58.

34. Rezaei O, Mokhayeri Y, Haroni J, Rastani MJ, Sayadnasiri M, Ghisvand H, et al. Association between sleep quality and quality of life among students: a cross sectional study. Int J Adolesc Med Health. 2017;32(2).

35. Human Development Index (HDI). https://datacatalog.worldbank.org/ human-development-index-hdi.

36. Begg CB, Mazumdar M. Operating characteristics of a rank correlation test for publication bias. Biometrics. 1994:50(4):1088-101.

37. Egger M, Smith GD, Schneider M, Minder C. Bias in meta-analysis detected by a simple, graphical test. Bmj. 1997:315(7109):629-34

38. Du R, Yiu C, King N. Health-and oral health-related quality of life among preschool children with autism spectrum disorders. Eur Arch Paediatr Dent 2020;21(3):363-71.

39. de Paula JS, Leite ICG, de Almeida AB, Ambrosano GMB, Mialhe FL. The impact of socioenvironmental characteristics on domains of oral healthrelated quality of life in Brazilian schoolchildren. BMC Oral Health. 2013; 13(1):10.

40. Nanayakkara V, Renzaho A, Oldenburg B, Ekanayake L. Ethnic and socioeconomic disparities in oral health outcomes and quality of life among Sri Lankan preschoolers: a cross-sectional study. Int J Equity Health. 2013;12(1):89.

41. Shearer DM, Thomson WM, Broadbent JM, Poulton R. Does maternal oral health predict child oral health-related quality of life in adulthood? Health Qual Life Outcomes. 2011;9(1):50.

42. Gatto RCJ, Garbin AJÍ, Corrente JE, Garbin CAS. The relationship between oral health-related quality of life, the need for orthodontic treatment and bullying, among Brazilian teenagers. Dent Press J Orthod. 2019;24(2):73-80.

43. Abanto J, Carvalho TS, Mendes FM, Wanderley MT, Bönecker M, Raggio DP. Impact of oral diseases and disorders on oral health-related quality of life of preschool children. Community Dent Oral Epidemiol. 2011;39(2):105-14.

44. Martins-Júnior P, Vieira-Andrade R, Corrêa-Faria P, Oliveira-Ferreira F, Marques L, Ramos-Jorge M. Impact of early childhood caries on the oral health-related quality of life of preschool children and their parents. Caries Res. 2013:47(3):211-8.

45. Chaffee BW, Rodrigues PH, Kramer PF, Vítolo MR, Feldens CA. Oral healthrelated quality-of-life scores differ by socioeconomic status and caries experience. Community Dent Oral Epidemiol. 2017:45(3):216-24.

46. Piovesan C, Antunes JLF, Guedes RS, Ardenghi TM. Impact of socioeconomic and clinical factors on child oral health-related quality of life (COHRQoL). Qual Life Res. 2010;19(9):1359-66.

47. Tomazoni F, Zanatta FB, Tuchtenhagen S, da Rosa GN, Del Fabro JP, Ardenghi TM. Association of gingivitis with child oral health-related quality of life. J Periodontol. 2014:85(11):1557-65.

48. Wong $\mathrm{H}, \mathrm{McGrath} \mathrm{C}$, King $\mathrm{N}$, Lo E. Oral health-related quality of life in Hong Kong preschool children. Caries Res. 2011;45(4):370-6.

49. Leal S, Bronkhorst E, Fan M, Frencken J. Untreated cavitated dentine lesions: impact on children's quality of life. Caries Res. 2012;46(2):102-6.

50. O'Brien K, Wright JL, Conboy F, Macfarlane T, Mandall N. The child perception questionnaire is valid for malocclusions in the United Kingdom. Am J Orthod Dentofac Orthop. 2006;129(4):536-40.

51. Agou S, Locker D, Streiner DL, Tompson B. Impact of self-esteem on the oral-health-related quality of life of children with malocclusion. Am J Orthod Dentofac Orthop. 2008:134(4):484-9.

52. Foster Page LA, Thomson WM, Ukra A, Farella M. Factors influencing adolescents' oral health-related quality of life $(\mathrm{OHRQ} \circ \mathrm{L})$. Int J Paediatr Dent. 2013;23(6):415-23.

53. Honkala S, Honkala E, Al-Sahli N. Do life-or school-satisfaction and selfesteem indicators explain the oral hygiene habits of schoolchildren? Community Dent Oral Epidemiol. 2007;35(5):337-47.

54. López R, Baelum V. Oral health impact of periodontal diseases in adolescents. J Dent Res. 2007;86(11):1105-9.

55. Marshman Z, Rodd H, Stern M, Mitchell C, Locker D, Jokovic A, Robinson P. An evaluation of the child perceptions questionnaire in the UK. Community Dent Health. 2005:22(3):151. 
56. Tarride J-E, Burke N, Bischof M, Hopkins RB, Goeree L, Campbell K, Xie F, O'Reilly D, Goeree R. A review of health utilities across conditions common in paediatric and adult populations. Health Qual Life Outcomes. 2010;8(1):12.

57. Crosby R, Noar SM. What is a planning model? An introduction to PRECEDEPROCEED. J Public Health Dent. 2011;71:S7-S15.

58. Sheiham A, Sabbah W. Using universal patterns of caries for planning and evaluating dental care. Caries Res. 2010;44(2):141-50

59. Petersen $P E$, Kwan $S$. Evaluation of community-based oral health promotion and oral disease prevention-WHO recommendations for improved evidence in public health practice. Community Dent Health. 2004;21 (4):319-29.

\section{Publisher's Note}

Springer Nature remains neutral with regard to jurisdictional claims in published maps and institutional affiliations.

Ready to submit your research? Choose BMC and benefit from:

- fast, convenient online submission

- thorough peer review by experienced researchers in your field

- rapid publication on acceptance

- support for research data, including large and complex data types

- gold Open Access which fosters wider collaboration and increased citations

- maximum visibility for your research: over $100 \mathrm{M}$ website views per year

At BMC, research is always in progress.

Learn more biomedcentral.com/submissions 